\title{
Aspectos clínicos e o hemograma em crianças expostas ao HIV-1: comparação entre pacientes infectados e soro-reversores
}

\author{
Clinical aspects and complete blood counts in children exposed to HIV-1: \\ comparison between infected patients and seroreverters
}

\author{
Elianete B. Silva ${ }^{1}$, Helena Z.W. Grotto ${ }^{2}$, Maria Marluce S. Vilela ${ }^{3}$
}

\section{Resumo}

Objetivo: analisar evolutivamente aspectos clínicos e hematológicos de crianças expostas à transmissão vertical do HIV-1 e comparar as que se infectaram com aquelas que não se infectaram, ou soro-reversoras.

Métodos: trata-se de estudo prospectivo, descritivo, longitudinal. Foram analisadas 79 crianças, filhas de mães infectadas pelo HIV-1, sob seguimento entre março de 1996 a novembro de 1997, no Ambulatório de Imunodeficiência do Hospital de Clínicas da Unicamp.

Resultados: houve comprometimento pôndero-estatural em ambos os grupos, sendo maior nos soro-reversores. No grupo das crianças infectadas, 23 mães não fizeram terapia com AZT na gestação, 16 pacientes $(61,5 \%)$ foram amamentados ao seio, quatro foram classificadas na categoria clínica $\mathrm{N}$, sete na $\mathrm{A}$, e 15 na $\mathrm{B}$. Manifestações clínicas antes de um ano de idade ocorreram em 18 lactentes $(69,2 \%)$. Anemia se manifestou em $73,1 \%$ das crianças infectadas, e em $41,5 \%$ das com soro-reversão ( $\mathrm{p}<0,008)$. A comparação entre os grupos mostrou que as alterações mais freqüentes nos infectados foram microcitose e hipocromia $(\mathrm{p}<0,05)$, linfopenia entre 15 e 18 meses $(p<0,05)$, monocitose entre os 9 e 12 meses $(\mathrm{p}<0,05)$ e uma tendência de altos níveis séricos de ferritina, mas sem significância estatística.

Conclusões: anemia microcítica e hipocrômica ocorreu em ambos os grupos, sendo ferropriva entre os soro-reversores, e anemia de doença crônica, entre os infectados. Nesse referido grupo, monocitose e linfopenia foram manifestações precoces.

J Pediatr (Rio J) 2001; 77 (6): 503-11: síndrome da imunodeficiência adquirida, anemia, linfopenia.

\section{Introdução}

$\mathrm{Na}$ América Latina e no Caribe, a AIDS (Acquired Immunodeficiency Syndrome - Síndrome da Imunodeficiência Adquirida) se espalhou com mais intensidade entre

1. Mestre em Medicina, área de Pediatria, Unicamp.

2. Professora Assistente Doutora do Departamento de Patologia Clínica.

3. Professora Livre-docente do Departamento de Pediatria da Unicamp. Fonte financiadora: FAPESP.

Artigo submetido em 14.08.00, aceito em 17.07.01.

\section{Abstract}

Objective: to analyze the evolution of clinical and hematological aspects of children exposed to the vertical transmission of HIV1 , comparing infected patients with uninfected ones or seroreverters.

Methods: prospective, descriptive, longitudinal study. We analyzed 79 children born from HIV-1 infected mothers, under clinical follow up from March, 1996 until November, 1997, at the Immunodeficiency division of the Hospital de Clínicas da Unicamp (State University Hospital of Campinas).

Results: failure to thrive was observed in both groups, but was greater among seroreverters. Among the infected children, 23 mothers did not use AZT during pregnancy, 16 of them (61.5\%) had been breastfed, four were classified into clinical category $\mathrm{N}$, seven into A and fifteen into B. Clinical manifestations in patients younger than one year were seen in 18 infected children (69.2\%). Anemia was observed in $73.1 \%$ of the infected group and in $41.5 \%$ of the seroreverters $(\mathrm{P}<0.008)$. The comparison between the groups showed that the most common hematologic alterations in the infected children was microcytosis and hypochromia $(\mathrm{P}<0.05)$, lymphopenia between 15 and 18 months $(\mathrm{P}<0.05)$, monocytosis between 9 and 12 months $(\mathrm{P}<0.05)$ and a tendency towards high ferritin levels, with no statistical significance.

Conclusions: microcytic and hypochromic anemia were observed in both groups: iron deficiency in the uninfected children, and chronic disease anemia in the infected ones. The infected children presented with monocytosis and lymphopenia at an earlier stage.

J Pediatr (Rio J) 2001; 77 (6): 503-11: acquired immunodeficiency syndrome, anemia, lymphopenia.

as mulheres e, em conseqüência, elevou a taxa de transmissão vertical. No Brasil, entre 1998-1999, 90,2\% dos casos de AIDS em crianças abaixo de 13 anos foram atribuídos à transmissão vertical ${ }^{1}$. No Estado de São Paulo, a taxa de transmissão vertical do HIV foi de $16 \%$, sendo que, na população estudada, havia $12 \%$ de mães com doença avançada, e $39 \%$ de crianças em aleitamento materno ${ }^{2}$. 
O vírus da imunodeficiência humana do tipo 1 (HIV-1) pode ser transmitido in útero, durante o trabalho de parto, e no pós-parto, através do leite materno. O diagnóstico precoce da infecção pode ser feito pelo PCR-DNA (Protein Chain Reaction) em linfócitos do sangue do cordão umbilical, ou periférico em até $30 \%$ dos recém-nascidos infectados, sugerindo infecção in útero ${ }^{3}$. Os lactentes infectados que não receberam o aleitamento materno (mais de $75 \%$ ) são PCR-DNA negativos ao nascimento e, após 2 a 4 semanas de vida, tornaram-se positivos, sugerindo que a transmissão tenha sido intraparto ${ }^{4}$.

A infecção pelo HIV-1 e a conseqüente síndrome da imunodeficiência podem determinar alterações hematológicas importantes na criança, não somente na fase avança$\mathrm{da}^{5}$, mas também durante a fase de latência clínica e início das manifestações da infecção. Anormalidades hematológicas podem ser atribuídas aos efeitos diretos e indiretos da infecção pelo HIV-1, às infecções oportunísticas e à toxicidade dos agentes terapêuticos.

No adulto, na fase da infecção primária, pode ocorrer inicialmente linfopenia, seguida por linfocitose e atipia linfocitária, neutropenia, trombocitopenia e pancitopenia transitória. Durante a fase assintomática, há uma queda gradual no número de linfócitos TCD4+, que pode inicialmente ser mascarada pela linfocitose atribuída a um aumento das células TCD8+. No momento em que ocorre a definição do diagnóstico de AIDS, há linfopenia e, freqüentemente, pancitopenia. Anemia é geralmente normocítica e normocrômica, mas algumas vezes macrocítica, mesmo na ausência de terapia com AZT (zidovudina) e, ocasionalmente, podem existir anemia hemolítica microangiopática ou púrpura trombocitopênica trombótica 6 .

O sistema imune funciona não somente como substrato para a replicação do HIV-1, bem como para defesa. Assim, as diferenças entre o sistema imune do hospedeiro adulto e o da criança, ainda em desenvolvimento, devem contribuir para as particularidades complexas da patogênese dessa infecção na infância.

Parâmetros laboratoriais quantitativos e qualitativos, as manifestações clínicas, as infecções oportunísticas e as neoplasias que acompanham a AIDS, em pediatria, diferem daqueles dos adultos.

É possível que anormalidades como anemia ${ }^{7}$, linfopenia, leucopenia, neutropenia, hipossegmentação de neutrófilos, alterações nos monócitos, plaquetopenia e mielodisplasia ${ }^{7,9}$, descritas inicialmente por Spivak et al. ${ }^{8}$, sejam alterações precoces e persistentes na criança infectada pelo HIV-1 por transmissão vertical. Também é provável que múltiplos fatores contribuam para as diferenças na capacidade das células do feto e do recém-nascido de se infectar ou de suportar a replicação viral.

Sendo assim, o presente estudo teve como objetivo analisar aspectos clínicos e hematológicos, especialmente o hemograma e o nível de ferritina sérica, em crianças expostas à transmissão vertical do HIV-1, comparando as que se infectaram com aquelas não-infectadas.

\section{Métodos}

Foi feito um estudo prospectivo, descritivo, longitudinal. A definição de infecção pelo HIV-1 e a classificação clínica seguem os critérios do CDC (Centers for Disease Control $)^{10}$ e da "Revisão da Definição Nacional de Casos de AIDS em Crianças", do Ministério da Saúde, de $1994^{11}$. Os pacientes que, durante sua evolução, se mantiveram assintomáticos foram classificados na categoria "N", os pacientes com sintomas leves, na categoria "A", sintomas moderados, na "B" e graves, na "C". A divisão dessas categorias em subitens de 1 a 3 identifica a categoria imunológica. A contagem absoluta e relativa dos linfócitos TCD4+, de acordo com a idade da criança, é usada para essa avaliação. Categoria 1 indica sistema imune relativamente intacto, categoria 2, leve (queda de TCD4+<10\%) a moderada imunossupressão (queda de TCD4+ entre 10 a 20\%), e grave na 3 (queda de TCD4+>20\%).

Foram analisadas 79 crianças sob acompanhamento no Ambulatório de Imunodeficiência do Hospital de Clínicas da Unicamp, de ambos os gêneros, cujas mães estavam infectadas pelo vírus da imunodeficiência humana tipo 1 , durante a gestação. O período de seguimento incluiu março de 1996 até novembro de 1997, e a amostra foi dividida em dois grupos: pacientes que apresentaram manifestações clínicas e exames laboratoriais confirmando a infecção pelo HIV-1, e aqueles classificados como soro-reversores ou não-infectados.

Além da sorologia por Elisa e Western Blot, também foi realizado o PCR-DNA para diagnóstico de infecção pelo HIV-1.

O protocolo clínico e laboratorial de cada paciente foi realizado em intervalos de 3 meses até os 18 meses de idade, e, posteriormente, em intervalos de 6 meses. Incluíram-se também aquelas crianças que iniciaram anti-retrovirais na evolução da infecção. Esse protocolo foi submetido à comissão de ética médica do Hospital das Clínicas da Unicamp e aprovado sem restrições. Os pacientes e seus responsáveis foram informados sobre a pesquisa e seus consentimentos foram obtidos por escrito.

As medidas antropométricas utilizadas foram as obtidas na primeira consulta. A análise foi feita através do escore $\mathrm{Z}$ (dois desvios-padrões abaixo da média), utilizando-se o "Siscres W - sistema para análise de dados antropométricos", versão 1.0, desenvolvido por Morcillo et al. ${ }^{12}$, que utiliza como parâmetros de referência dados do NCHS (National Center for Health Statistics).

As técnicas dos exames realizados e respectivos valores de referência foram os mesmos citados por Silva et al. ${ }^{5}$

O PACTG 076 (Pediatric AIDS Clinical Trials Group 076) consiste no uso de zidovudina (AZT) via oral, entre a $14^{\mathrm{a}}$ e $34^{\mathrm{a}}$ semana de gestação, contínuo durante a gravidez, seguido por AZT intravenoso durante o parto e administração oral para o lactente, nas primeiras seis semanas de vida, mesmo sem diagnóstico confirmado. Nesse protocolo, foi incorporada também a recomendação para evitar o aleitamento materno ${ }^{13}$. 
O banco de dados foi implantado utilizando-se o software Epi Info 6.04-b. A análise estatística foi realizada com o SAS (Statistical Analyses System). Para verificar a associação entre quaisquer duas variáveis, utilizou-se o teste do Qui-quadrado e, quando este não se aplicava, utilizou-se o teste exato de Fisher.

Para rejeição da hipótese nula, utilizou-se o nível de significância de a $<5 \%$.

\section{Resultados}

Do grupo total de 79 crianças, 26 infectadas e 59 sororeversoras, $38(48,1 \%)$ eram do gênero masculino e 41 $(51,9 \%)$, do feminino. A Tabela 1 mostra as características dos dois grupos quanto ao gênero, ao aleitamento materno, ao uso de AZT na gestação (apenas via oral) e aos medicamentos utilizados. Apenas uma mãe do grupo dos sororeversores usou AZT endovenoso durante o parto, porque, até outubro de 1997, ainda não havia sido implantado completamente o protocolo PACTG 076 no serviço de obstetrícia do CAISM - Unicamp.

A idade de início de acompanhamento variou de 20 dias até 7 anos e 9 meses e, ao final, foi de 8 meses e 15 dias até 8 anos e 4 meses. A idade mediana foi de 2 anos e 2 meses para o total de crianças infectadas, e de 9 meses para as nãoinfectadas, sendo 2 anos e 7 meses e 1 ano e 3 meses as médias de idades respectivas.

Tabela 1 - Características dos pacientes expostos à transmissão vertical do HIV-1, infectados e soro-reversores, e medicamentos utilizados

\begin{tabular}{lcccc}
\hline $\begin{array}{l}\text { Características } \\
\text { da amostra }\end{array}$ & Infectados & \multicolumn{3}{c}{$\begin{array}{c}\text { Soro- } \\
\text { reversores }\end{array}$} \\
& n=26 & $\%$ & n=53 & \% \\
\hline Gênero & & & & \\
$\quad$ feminino & 17 & 65,4 & 24 & 45,3 \\
$\quad$ masculino & 9 & 34,6 & 29 & 54,7 \\
$\quad$ Aleitamento materno & & & & \\
$\quad$ Sim & 16 & 61,5 & 8 & 15,1 \\
$\quad$ Não & 10 & 38,5 & 45 & 84,9 \\
Uso de AZT na gestação & & & & \\
$\quad$ Sim & 3 & 11,5 & 10 & 18,9 \\
$\quad$ Não & 23 & 88,5 & 43 & 81,1 \\
Zidovudina (AZT) & 19 & 73,1 & 10 & 18,9 \\
Didanosina (DDI) & 17 & 65,4 & 0 & 0 \\
SMX-TMP & 23 & 88,5 & 36 & 67,8 \\
Sulfato ferroso & 13 & 50,0 & 20 & 37,7 \\
Antibióticos & 9 & 34,6 & 6 & 11,3 \\
\hline
\end{tabular}

$\mathrm{n}=$ número total de pacientes
A avaliação clínico-imunológica inicial identificou 4 pacientes na categoria $\mathrm{N}$, sendo 2 na $\mathrm{N} 1 ; 7$ no grupo $\mathrm{A}$, sendo 1 na A1, 5 na A2 e 1 na A3; e 15 no grupo B, 4 na B1, 3 na $\mathrm{B} 2$ e 8 na B3.

\section{Avaliação antropométrica e manifestações clínicas}

No grupo de crianças soro-reversoras, 7 (13,2\%) estavam com peso abaixo do segundo escore Z, e $11(20,7 \%)$ apresentaram estatura abaixo desse escore. Durante o primeiro ano de vida, em 30 dessas crianças foi observado o seguinte: síndrome anêmica em 8 (26,6\%); baixo ganho ponderal em $5(16,7 \%)$; síndrome asmatiforme com diagnóstico de refluxo gastresofágico em 3 (10\%); alergia, dermatite inespecífica, otite média aguda, infecção de vias aéreas superiores (IVAS) em 2 (6,7\%). Outros diagnósticos, como desnutrição proteico-calórica, escabiose, monilíase oral e perineal, tuberculose, pneumonia, sinusopatia, infecção congênita por citomegalovírus (CMV), toxoplasmose, rubéola e sífilis, além de plaquetopenia, foram observados.

No grupo de crianças infectadas, apenas duas $(7,7 \%)$ apresentavam peso e estatura abaixo de dois desvios-padrões para a idade. As manifestações da doença ocorreram em $18(69,2 \%)$ pacientes antes de um ano de vida, e em 7 após essa idade, sendo desconhecidas em 1 criança institucionalizada. Os diagnósticos mais freqüentes foram: síndrome linfoproliferativa em 7 crianças $(38,9 \%)$, pneumopatia crônica em $3(16,6 \%)$, hepatoesplenomegalia e síndrome anêmica em 2 pacientes $(11,1 \%)$, estrófulo, monilíase oral, pneumonias de repetição, pneumonite intersticial linfóide, esplenomegalia, diarréia aguda, infecção congênita por CMV, entre outros.

\section{Análise comparativa da série vermelha, por faixa etária}

A periodicidade dos exames não pôde ser sempre ideal, em virtude de faltas eventuais às consultas e às coletas laboratoriais. Foram analisados 345 hemogramas. Para a análise estatística, selecionamos apenas um exame em cada faixa etária, e, por esse motivo, o número de hemogramas analisados foi reduzido para 193.

A freqüência comparativa de anemia entre infectados pelo HIV-1 e soro-reversores está demonstrada nas Figuras 1,2 , e 3, assim como a evolução da microcitose, da hipocromia e da macrocitose. Anemia é mais freqüente nos infectados entre 9 e 12 meses ( $\mathrm{p}<0,05)$, oscila entre 17 e $60 \%$ até os 30 meses, dos 30 aos 36 meses ocorre em 100\% dessas crianças $(\mathrm{p}<0,05)$, para, em seguida, manter maior freqüência no grupo de infectados, exceto aos 4 anos e 5 anos e 6 meses. A microcitose mantém-se nos dois grupos de forma regular até os 48 meses, e a hipocromia é predominante entre os infectados com 30 e 36 meses $(p<0,05)$. Macrocitose foi observada em $100 \%$ das crianças infectadas entre zero e 3 meses de idade, e em 5 (56\%) dos nãoinfectados. As mães dessas crianças usaram AZT na gesta- 


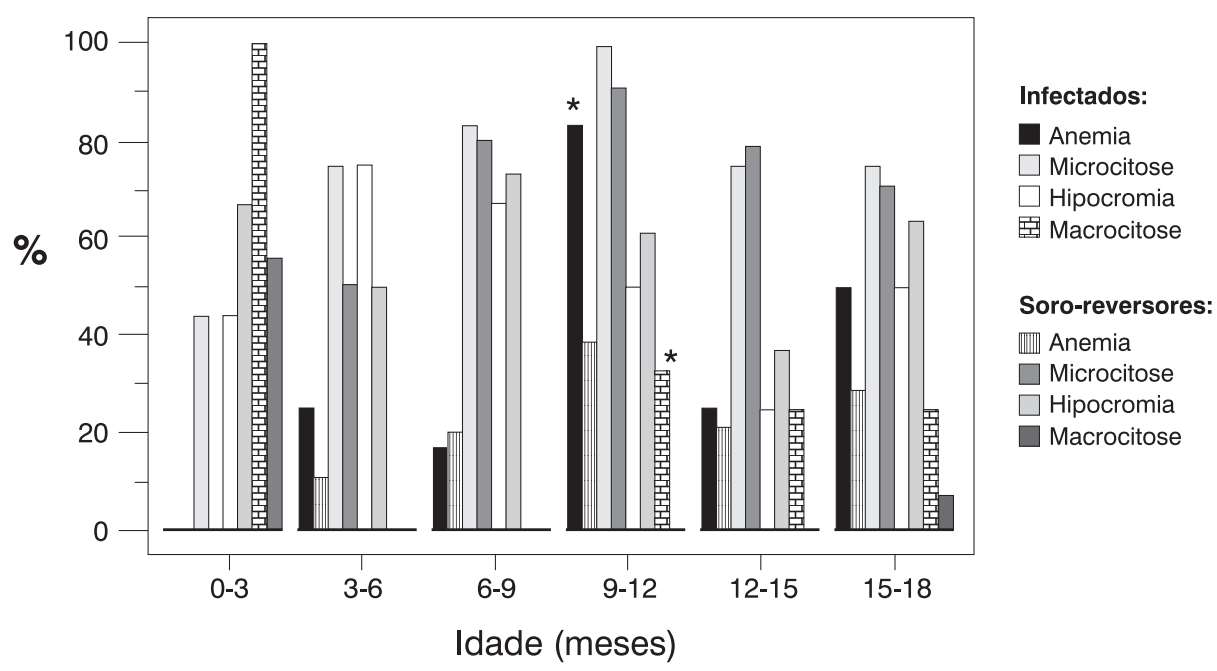

Figura 1 - Evolução da anemia, microcitose, hipocromia e macrocitose em crianças infectadas pelo HIV-1 e soro-reversoras, na faixa etária de 0 a 18 meses (os asteriscos indicam os grupos etários em que se observaram diferenças estatisticamente significativas)

ção, e os bebês, durante 6 semanas, havendo três que usaram também SMX-TMP e um, isoniazida. Macrocitose foi detectada novamente entre os 9 e 12 meses de idade em $33 \%$ dos infectados, e não é observada entre os com sororeversão $(\mathrm{p}<0,05)$.

Em resumo, pode-se dizer que anemia se manifestou em $73,1 \%$ das crianças infectadas e em $41,5 \%$ dos soro-reversores com diferença significativa ( $\mathrm{p}=0,008)$, mas não houve associação com a categoria clínica imunológica.

\section{Análise comparativa da série branca}

A freqüência comparativa do número de leucócitos, neutrófilos e linfócitos pode ser verificada nas Figuras 4, 5 e 6 .

No grupo de crianças com soro-reversão foi observada leucocitose entre 6 e 15 meses, leucopenia a partir dos 6 meses, neutropenia, linfopenia e atipia linfocitária, em baixa freqüência, até os 18 meses de idade, notando-se 33\% com atipia linfocitária entre 6 e 9 meses. Considerando-se

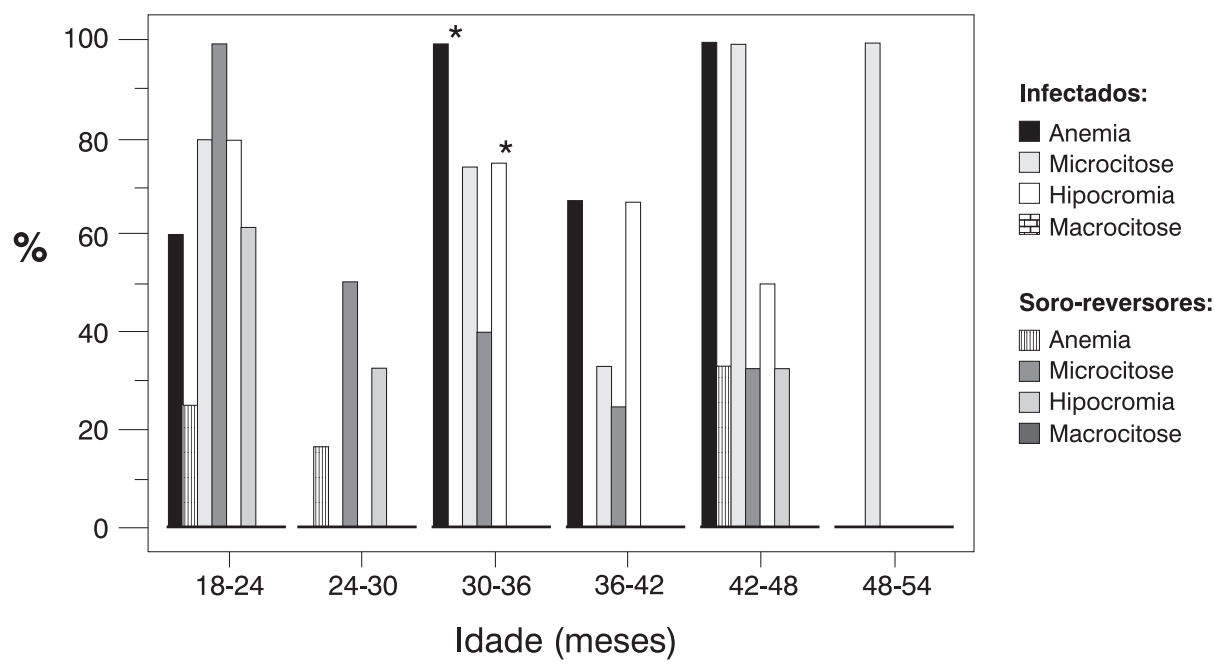

Figura 2 - Evolução da anemia, microcitose, hipocromia e macrocitose em crianças infectadas pelo HIV-1 e soro-reversoras, na faixa etária de 18 a 54 meses (os asteriscos indicam os grupos etários em que se observaram diferenças estatisticamente significativas) 


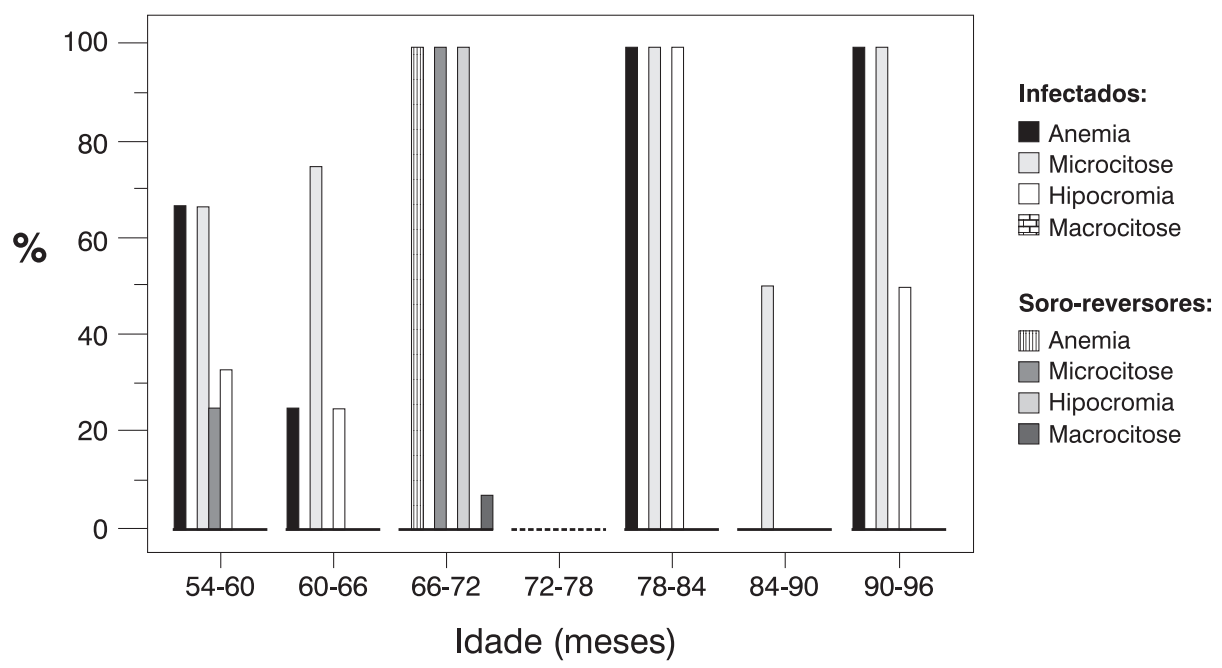

Figura 3 - Evolução da anemia, microcitose, hipocromia e macrocitose em crianças infectadas pelo HIV-1 e soro-reversoras, na faixa etária de 54 a 96

o total de exames realizados, $22,6 \%$ dos soro-reversores apresentaram linfopenia. Eosinofilia foi vista em um paciente antes dos 3 meses, em 1 antes dos 6 meses, e em 5 casos antes dos 4 anos. Monocitose manifestou-se em $56 \%$ dos indivíduos antes dos 3 meses, entre $26 \%$ a $28 \%$ até os 12 meses, mantendo-se entre 20 a $40 \%$ dos casos até os 42 meses.

No grupo de crianças infectadas pelo HIV-1 não foi observado leucocitose, sendo que neutropenia apareceu em baixa freqüência até os 18 meses, e se manteve após os 48 meses. Atipia linfocitária foi significativamente mais elevada no grupo de infectados (83\%) do que no grupo com soro-reversão $(33 \%)(\mathrm{p}<0,05)$, entre 6 e 9 meses. Observamos linfopenia predominando nos infectados após 12 meses, elevando-se a freqüência para $75 \%$ entre 15 e 18 meses $(\mathrm{p}<0,05)$. Essa tendência manteve-se nas demais faixas etárias. Considerando-se o total de hemogramas, $38,5 \%$ dos pacientes com infecção pelo HIV-1 apresentaram linfo-

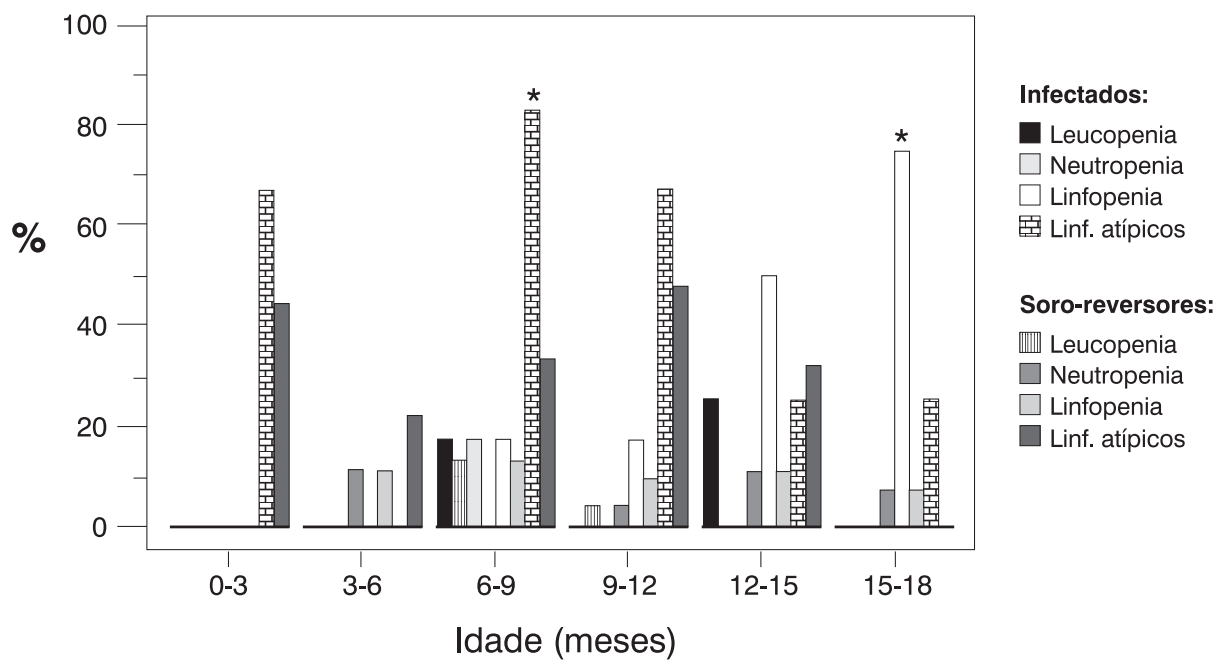

Figura 4 - Evolução da leucopenia, neutropenia, linfopenia e atipia linfocitária em crianças infectadas pelo HIV-1 e soro-reversoras, na faixa etária de 0 a 18 meses (os asteriscos indicam os grupos etários em que se observaram diferenças estatisticamente significativas) 


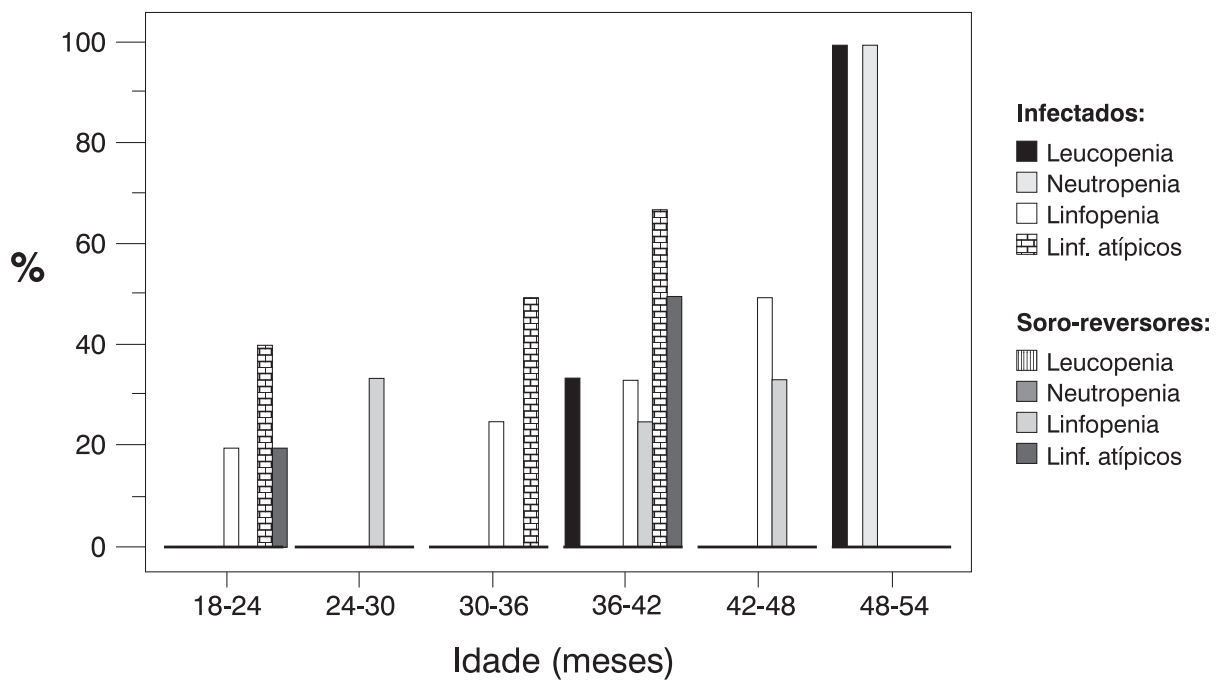

Figura 5 - Evolução da leucopenia, neutropenia, linfopenia e atipia linfocitária em crianças infectadas pelo HIV-1 e soro-reversoras, na faixa etária de 18 a 54 meses

penia em comparação com $22,6 \%$ dos soro-reversores $(\mathrm{p}=$ 0,140). Não houve associação entre a linfopenia e a classificação clínica imunológica da infecção ( $\mathrm{p}=0,297)$.

Eosinofilia ocorreu em 1 caso antes dos 6 meses e eventualmente após os 5 anos de idade. A monocitose ocorreu entre $50 \%$ a $67 \%$ das crianças até os 9 meses, e em $83 \%$ delas, entre 9 e 12 meses, com diferença significativa entre os dois grupos $(\mathrm{p}<0,05)$. Até os 42 meses, manteve-se entre 20 e $40 \%$ dos indivíduos de ambos os grupos, e então decresce.

\section{Análise comparativa da série plaquetária}

No grupo de não-infectados ou soro-reversores, a plaquetose foi encontrada em $33 \%$ das crianças antes dos 3 meses de idade e dos 3 aos 6 meses. Até os 2 anos, variou entre $14 \%$ e $27 \%$. Plaquetopenia foi diagnosticada em um

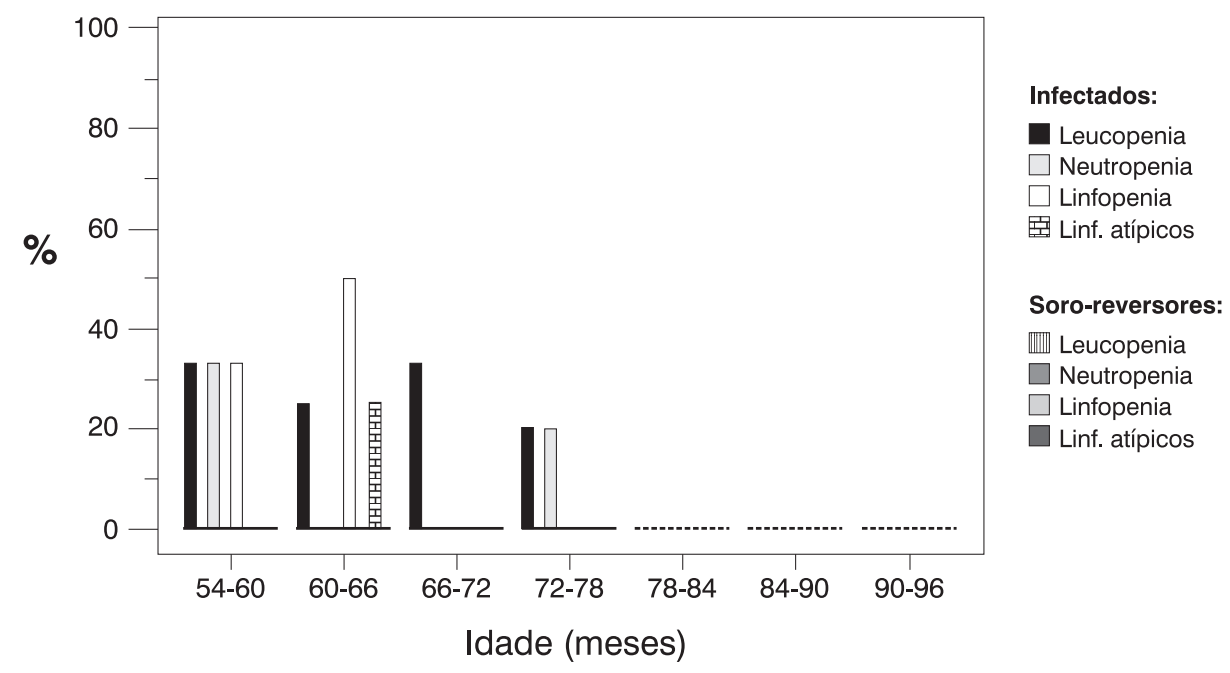

Figura 6 - Evolução da leucopenia, neutropenia, linfopenia e atipia linfocitária em crianças infectadas pelo HIV-1 e soro-reversoras, na faixa etária de 54 a 96 meses 
caso entre 3 e 6 meses, entre 9 e 12 meses e ainda entre 12 e 15 meses.

No grupo de infectados, ocorreu plaquetose em 33\% das crianças antes dos 3 meses de idade, um caso entre os 6 e 9 meses, e um caso entre 36 e 42 meses. Plaquetopenia foi diagnosticada em um paciente aos 6 anos, e em outro aos 7 anos.

\section{Análise comparativa das concentrações séricas de ferritina, ferro e TIBC}

No grupo de pacientes com soro-reversão, foram realizadas 68 dosagens de ferritina sérica, havendo $11(16,2 \%)$ indivíduos com valores abaixo do normal, 52 (76,5\%) normais, e $5(7,3 \%)$ elevados. Foram obtidas 13 dosagens de ferro sérico, sendo $2(15,4 \%)$ com valores reduzidos, 10 (77\%) normais e um elevado, em um paciente que recebia sulfato ferroso. Das 9 amostras com dosagem de TIBC, 3 $(33,3 \%)$ apresentaram valores normais, e $6(66,7 \%)$ acima do valor de referência.

Entre as crianças infectadas, $5(17,9 \%)$ apresentaram valores de ferritina sérica reduzidos, $16(57,1 \%)$ níveis normais, e 7 (25\%) níveis elevados. Não houve diferença significativa entre os dois grupos. A concentração sérica de ferro estava abaixo do normal em 7 pacientes (50\%), e o restante dentro da normalidade. Das 8 amostras com dosagem de TIBC, 4 (50\%) apresentavam níveis elevados, e as demais, normais.

\section{Discussão}

A desnutrição crônica diagnosticada pelo maior comprometimento da estatura entre os soro-reversores indica que o suporte nutricional, cesta básica e leite, oferecido apenas ao grupo das crianças infectadas, fez a grande diferença nos resultados antropométricos deste estudo. No balanço infecção e nutrição, o fator social emergiu como marcador determinante da desnutrição e precocidade da manifestação da infecção pelo HIV-1. A precariedade da qualidade de vida, além da situação de saúde dos progenitores, os custos e a complexidade do tratamento, o desemprego e a orfandade acentuam as deficiências nutricionais.

A diferença significativa entre os dois grupos quanto ao aleitamento materno confirma que esta prática entre as mães infectadas pelo HIV-1 acrescentou risco adicional à transmissão perinatal. Além disso, das 15 mães que usaram AZT na gestação, apenas uma recebeu AZT endovenoso durante o parto, e 13 bebês foram tratados durante as 6 primeiras semanas. A falha no estabelecimento completo do PACTG 076 contribuiu para a manutenção de taxa elevada (20\%) de transmissão vertical do HIV-1.

Nos EUA e na França, a incorporação na prática clínica do protocolo PACTG076, em 1994, reduziu de modo dramático a transmissão perinatal ${ }^{13}$. No Brasil, nos serviços em que este já foi devidamente incorporado, observou- se um impacto importante na prevenção dessa transmissão do HIV-1, como no Centro Municipal de DST/AIDS de Porto Alegre (RS), com 2,6\% de taxa de transmissão perinatal entre $1999-2000^{14}$.

Nas crianças infectadas pelo HIV-1 e nas com sororeversão, observamos anemia microcítica e hipocrômica a partir do $3^{\circ}$ mês. Comparando esses dois grupos aos 9 e aos 30 meses, houve diferença estatisticamente significativa $(\mathrm{p}<0,05)$, assim como no total de pacientes, com maior freqüência de anemia entre os infectados $(73,1 \%)$ do que entre os soro-reversores $(41,5 \%)$.

$\mathrm{Na}$ análise desses resultados, deve-se considerar várias particularidades. Em primeiro lugar, na criança não exposta ao HIV-1, a hemoglobina cai de $18 \mathrm{~g} / \mathrm{dl}$ ao nascimento para $14 \mathrm{~g} / \mathrm{dl}$ com 2 semanas de vida. O ferro liberado é armazenado e reutilizado gradualmente, quando a massa total de hemoglobina circulante começa a aumentar com o crescimento. Entre os 4 e 12 meses, o ferro corporal total duplica, e uma fonte externa de ferro é necessária ${ }^{15}$. Se isso não ocorre, como na população deste estudo, se desenvolve anemia precocemente.

De acordo com a literatura, o tipo de anemia predominante nas crianças infectadas é hipocrômica (40\%) e microcítica (56\%), ocorrendo ainda anisocitose e poiquilocito$\mathrm{se}^{7,9}$. Além disso, o baixo teor de ferro corporal entre as mães gestantes com infecção pelo HIV-1, o uso dos antiretrovirais, a própria infecção pelo HIV-1 nas crianças, a inapetência, a dieta pobre em ferro, as infecções oportunísticas por bactérias, parvovírus B19, Micobacterium avium intracelulare, entre outras, contribuem para a gravidade $\mathrm{e}$ persistência da anemia.

Observamos $100 \%$ de macrocitose aos 3 meses nos infectados, embora não apresentassem anemia. Houve diferença significativa $(p<0,05)$ dessa alteração entre os 9 e 12 meses, e pode estar relacionada ao uso profilático (até 6 semanas de vida) ou terapêutico (aos 9 meses) de AZT, associado à profilaxia com SMX-TMP para Pneumocystis carinii.

A etiologia da anemia nas crianças infectadas ainda não está perfeitamente definida. Foram identificados 4 pacientes com anemia das doenças crônicas, e 2, com anemia ferropriva. Entretanto, havia 50\% dos infectados e 37,7\% dos soro-reversores recebendo sulfato ferroso, justificando que valores baixos de ferro fossem detectados apenas em 7 infectados e em 2 não-infectados. Castaldo et al. ${ }^{16}$ observaram baixos níveis de ferro em $48 \%$ de um grupo de crianças com infecção pelo HIV-1. Na anemia de doença crônica, a eritropoiese é limitada pela hipoferremia. Embora os níveis de eritropoietina estejam elevados, a medula óssea falha na resposta, provavelmente devido às alterações nas funções das citocinas IL-1, IL-3, IL-6, M-CSF, G-CSF, GM-CSF, TNF-RI e TNF-RII (receptores de TNF) ${ }^{17,18}$.

$\mathrm{Na}$ literatura, é sugerido que a anemia pode estar relacionada ao efeito citopático do HIV-1 sobre os eritrócitos, às alterações nas células do estroma medular ${ }^{19}$, à 
presença de anticorpos antieritrócitos ${ }^{20}$ ou não ${ }^{21}$, e à infecção das células progenitoras hematopoiéticas pelo HIV-1 ${ }^{22,23}$, ou não $0^{24}$.

Entre adultos infectados pelo HIV-1, anemia é muito comum, ocorrendo em aproximadamente $30 \%$ durante os anos iniciais assintomáticos e em 80 a $90 \%$ dos pacientes no curso da doença. É considerada anemia de doença crônica, predominando a anemia normocrômica e normocítica. Outras alterações, como poiquilocitose e anisocitose, ocorrem na maioria dos pacientes ${ }^{25}$.

A atipia linfocitária ocorreu antes de um ano de idade nas crianças infectadas, com diferença significativa entre os 6 e 9 meses, e linfopenia foi mais freqüente entre 15 e 18 meses. Na infecção pelo HIV-1, a principal deficiência imunológica é o declínio contínuo de linfócitos TCD4+. Os recém-nascidos normais têm uma porcentagem de linfócitos TCD4+ muito maior do que os adultos, com predomínio de células "naive" CD45RA+, comparada à população de células de memória CD45RO+. Com a idade, a porcentagem e o número absoluto de células TCD4+ no lactente começa a se aproximar aos valores dos adultos.

O declínio das células TCD4+ é freqüentemente muito mais rápido na infecção vertical do que nos adultos, e se correlaciona com a doença clínica. O timo atende a essa demanda até que ocorra exaustão, expressa pela linfopenia periférica ${ }^{26}$. Algumas crianças têm um declínio rápido em linfócitos TCD4+, resultando em diagnóstico precoce de AIDS, enquanto outros podem permanecer sadios e livres de sintomas por anos.

Considera-se que a elevação prolongada do número de cópias de RNA HIV-1 no início da infecção pode ser causado por um pool muito maior de TCD4+, mais permissiva à infecção pelo HIV-1, resultando em atipia e redução dos linfócitos. Em adição à perda de células TCD4+, um aumento nas células TCD8 também é observado. Embora esta seja uma visão simplificada do que está ocorrendo, algum grau de ativação imune vem da hipergamaglobulinemia e excesso de linfocinas circulantes ${ }^{27}$.

A etiologia da leucopenia e neutropenia observada nessa população de crianças infectadas pode ser atribuída à supressão da hematopoiese, como relatado por Scadden ${ }^{28}$, ou, ainda, ao uso de drogas mielotóxicas, às infecções oportunísticas e à presença de anticorpos antineutrófi$\operatorname{los}^{21,29}$.

A eosinofilia, eventual em ambos os grupos, foi considerada como resultado de parasitose intestinal e como sensibilização aos medicamentos. No grupo dos infectados, é possível que a eosinofilia e elevação de IgE correspondam à mudança de padrão de citocinas do tipo TH1 para TH2.

A monocitose, entre os infectados com diferença significativa entre os 9 e 12 meses de idade, demonstra que o HIV-1 explora os recursos do hospedeiro, no sentido de escapar à vigilância imunológica, à semelhança de outros patógenos intracelulares ${ }^{30}$.
A plaquetose foi eventual em ambos os grupos e foi atribuída ao descontrole da medula óssea após infecções, à deficiência de ferro ou vitamina $\mathrm{E}^{31}$, e também ao uso do AZT. A plaquetopenia foi rara entre os infectados, provavelmente porque ela é freqüente nos estágios avançados da infecção 9 .

Os dados nos permitem ponderar que o uso do AZT pelo par mãe-bebê contribuiu para redução da taxa de transmissão, e que houve associação entre o aleitamento materno e a evolução para infecção.

Estes resultados, tomados em conjunto, permitem as seguintes conclusões: 1) o déficit pôndero-estatural foi mais acentuado entre os soro-reversores; 2) as manifestações clínicas da infecção pelo HIV-1 ocorreram antes de um ano de idade em $69,5 \%$ dos pacientes; 3 ) no grupo de infectados, houve diferença significativa nas alterações, como anemia, hipocromia, macrocitose, atipia linfocitária, linfopenia e monocitose; 4) o tipo de anemia predominante em ambos os grupos foi microcítica e hipocrômica. Houve associação entre a freqüência de anemia e a evolução para infecção, tendo como etiologia mais freqüente neste grupo a anemia das doenças crônicas.

\section{Referências bibliográficas}

1. Brasil. Ministério da Saúde. Secretaria de Assistência à Saúde. Programa Nacional de DST/AIDS - Boletim Epidemiológico AIDS. Set/Nov. Brasília, Ministério da Saúde; 1999.

2. Tess BH, Rodrigues LC, Newell M, Dunn DT, Lago TDG, and the São Paulo collaborative study for vertical transmission of HIV-1. Breastfeeding, genetic, obstetric and other risk factors associated with mother-to child transmission of HIV-1 in São Paulo State, Brasil. Aids 1998;12:513-20.

3. Luzuriaga K, McQuilken P, Alimenti A, Somasundaran M, Hesselton R, Sullivan JL. Early viremia and immune responses in vertical Human Immunodeficiency Virus Type-1 infection. J Infect Dis 1993; 167:1008-13.

4. Krivine A, Firtion G, Cao L, Francoual C, Henrion R, Lebon P. HIV replication during the first weeks of life. Lancet 1992; 339:1187-89.

5. Silva BE, Silva MTN, Vilela MMS. Evolução de parâmetros hematológicos em um grupo de crianças infectadas pelo vírus da imunodeficiência humana do tipo 1 (HIV-1). J Ped 1999; 75 : 442-48.

6. Bain BJ. The hematological features of HIV infection. British J Hematol 1997; 99:1-8

7. Ellaurie M, Burns ER, Rubinstein A. Hematologic manifestations in pediatric HIV infection: severe anemia as a prognostic factor. Am J Pediatr Hematol Oncol 1990;12: 449-53.

8. Spivak JL, Bender BS, Quinn TC. Hematologic abnormalities in the acquired immune deficiency syndrome. Am J Med 1984;77:224-8.

9. Mueller BV. Hematological problems and their management in children with HIV infection. In: Pizzo PA, Wilfert CM, eds. Pediatric AIDS. The challenge of HIV infection in infants, children and adolescents. $2^{\mathrm{a}}$ ed. Baltimore: Willians \& Wilkins; 1994. p.591-601. 
10. Centers for Disease Control. 1994 Revised classification system for human immunodeficiency virus infection in children less than 13 years of age. MMWR 1994, 43:1-19.

11. Brasil. Ministério da Saúde. Secretaria de Assistência à Saúde. Programa Nacional de Controle de DST-AIDS. Revisão da Definição Nacional de casos de AIDS em crianças. Brasília: Ministério da Saúde; 1994.p.12.

12. Morcillo AM, Lemos-Marini SHV, Guimarey LM, Siscres W. Análise de dados antropométricos. Unicamp-Ciped; 1997.

13. Cooper ER, Nugent RP, Diaz C, Pitt J, Hanson C, Kalish LA, et al. After AIDS clinical trial 076: the changing pattern of zidovudine using during pregnancy, and the subsequent reduction in vertical transmission of human immunodeficiency virus in a cohort of infected woman and their infants. J Infect Dis 1996;174:1207-11.

14. Centro Municipal de DST/AIDS de Porto Alegre. Efetividade do protocolo do uso da zidovudina (ZDV) na prevenção da transmissão perinatal do HIV no Centro Municipal de DST/AIDS de Porto Alegre - RS. Anais do Fórum 2000 - I Fórum e II Conferência de Cooperação Técnica Horizontal da América Latina e do Caribe em HIV/Aids e DST; 2000 Nov 6-11; Rio de Janeiro, Brasil. RJ: Ministério da Saúde, 2000 v1.p.30.

15. Wharton BA. Iron deficiency in children: detection and prevention. British J Hematol 1999; 106:270-80.

16. Castaldo A, Tarallo L, Palomba E, Albano F, Russo S, Zuin G, et al. Iron deficiency and intestinal malabsorption in HIV disease. J Pediatr Gastroenterol Nutr 1996; 22:359-63.

17. Means RT, Krantz SB. Progress in understanding the pathogenesis of the anemia of chronic disease. Blood 1992; 80:1639-47.

18. Kreuzer K, Rockstroh JK, Jelkmann W, Theisen A, Spengler U, Sauerbruch T. Inadequate erythropoietin response to anaemia in HIV patients: relationship to serum levels of tumor necrosis factor-alpha, interleukin- 6 and their soluble receptors. Br J Haematol 1997; 96:235-39.

19. Scadden DT, Zeira M, Woon A, Wang Z, Schieve L, Ikeuchi K et al. Human immunodeficiency virus infection of human bone marrow fibroblasts. Blood 1990; 76:317-22.

20. Mcginniss MH, Macher AM, Rook AH, Alter HJ. Red cell autoantibodies in patients with acquired immune deficiency syndrome. Transfusion 1986; 26:405-9.

21. Van Der Lelie J, Lange JMA, Vos JJE, Van Dalen CM, Danner SA, Von Dem Borne AEGK. Autoimmunity against blood cells in human immunodeficiency-virus (HIV) infection. Br J Haematol 1987; 67: 109-14.

22. Donahue RE, Johnson MM, Zon LI, Clark SC, Groopman JE. Suppression of in vitro haematopoiesis following human immunodeficiency virus infection. Nature 1987; 326:280-83.
23. Scadden DT, Zon LI, Groopman JE. Pathophysiology and management of HIV-associated hematologic disorders. Blood 1989; 74:1455-63.

24. Molina JM, Scadden DT, Sakaguchi M, Fuller B, Woon A, Groopman JE. Lack of evidence for infection of or effect on growth of hematopoietic progenitor cells after in vivo or in vitro exposure to human immunodeficiency virus. Blood 1990; 76:2476-82.

25. Sullivan PS, Hansondl CS, Jones J1, Ward JW. Epidemiology of anemia in human immunodeficiency virus infected persons: results from the multistate adult and adolescent spectrum of HIV disease surveillance project. Blood 1998; 91:301-8.

26. Amadori A, Zamarchi R, Chieco-Bianchi L. CD4:CD8 ratio and HIV infection: the 'tap-and-drain' hypothesis. Immunol Today 1996; 17:414-17.

27. Palumbo P, Burchet S. Diagnosis of HIV Infection and markers of disease progression in infants and children. In: Pizzo AP, Wilfert CM, eds. Pediatric AIDS. Baltimore: William \& Wilkins; 1996. p.67-87.

28. Scadden DT. Hematologic disorders and growth factor support in HIV infection. Hem Onc Clin N Am 1996; 10:1149-61.

29. Weinberg GA, Gigliotti F, Stroncek DF, Eiber G, Kassmann B, Murante B, Korones DN. Lack of relation of granulocyte antibodies (antineutrophil antibodies) to neutropenia in children with human immunodeficiency virus infection. Pediatr Infec Dis J 1997; 16:881-4.

30. Damian RT. Parasite immune evasion and exploitation: reflections and projections. Parasitology 1997; 115: S169-75.

31. Manco-Johnson MJ. Hemostasis and bleeding disorders. In: Rudolph AM ed., Hoffman JIE, Rudolph CD coed. Rudolph's Pediatrics. $2^{\mathrm{a}}$ ed. Appleton \& Lange; 1996. p.1244.

Endereço para correspondência:

Dra. Maria Marluce S. Vilela

CIPED - Centro de Investigação em Pediatria -

Faculdade de Ciências Médicas

PO BOX 6111 - Unicamp

CEP 13081-970 - Campinas, SP

Fax: (19) 788.8970 - Fone: (19) 788.8963

E-mail:marluce@fcm.unicamp.br 